\title{
Erratum to: Clinical Characteristics and Treatment of Leprosy
}

\author{
Minh Van Hoang ${ }^{1}$ - Duc Van Bui ${ }^{1}$ - Thuy Linh Phung ${ }^{2}$
}

Published online: 7 December 2016

(C) Springer International Publishing AG 2016

\section{Erratum to: Curr Trop Med Rep}

DOI 10.1007/s40475-016-0095-x

In the Acknowledgement section of the original article, the author would like to add some text to acknowledged the contribution of the clinical photos in the article by Khoa Kim Nguyen, MD, Ho Chi Minh City, Vietnam.

The Acknowledgement should now read as: We would like to thank Mahmoud Bokhary, MD, for his valuable assistance with the bibliography of this article and also to Khoa Kim Nguyen, MD, Ho Chi Minh City, Vietnam, for the clinical photos in this article.

The online version of the original article can be found at http://dx.doi. org/10.1007/s40475-016-0095-x.

\section{Thuy Linh Phung}

tphung@bcm.edu

1 Department of Dermatology, University of Medicine and Pharmacy of Ho Chi Minh City, Ho Chi Minh City, Vietnam

2 Department of Pathology and Immunology, Baylor College of Medicine and Texas Children's Hospital, 1102 Bates Avenue, FC 0830.21, Houston, TX 77030, USA 